\title{
OS DESDOBRAMENTOS DO AMOR EM ÉROS, FILÍA E ÁGAPE EM "DÃO-LALALÃO", DE GUIMARÃES ROSA
}

\author{
CLARISSA CATARINA BARLETTA MARCHELLI ${ }^{1}$ \\ Universidade Estadual de Campinas, Instituto de Estudos da Linguagem \\ Programa de Pós-Graduação em Teoria e História Literária \\ Cidade Universitária “Zeferino Vaz” - 13083-970 - Campinas (SP) - Brasil \\ clarissa.catarinalgmail.com
}

\begin{abstract}
Resumo. $O$ desejo sexual de um jagunço por uma prostituta é razão suficiente para um pedido de casamento. Passados três anos de matrimônio no religioso e no civil, o relacionamento do matador com a meretriz sofre abalo quando do reencontro de um velho amigo e um tropeiro que o acompanha. Aparentemente ciumento, a insegurança de Soropita camufla uma vaidade. O presente artigo procura demonstrar em que medida o desdobramento do relacionamento de Soropita com Doralda dialoga com as três acepções de amor que o léxico grego comporta: Eros, Filía e Ágape, segundo os filósofos contemporâneos André Comte-Sponville e Paul Ricoeur. Palavras-chave: Guimarães Rosa; amor; Eros; Filía; Ágape.

Abstract. The sexual desire of a roughneck for a prostitute is reason enough for a marriage proposal. Three years of marriage in the religious and civil, the relationship of the murderer with the prostitute suffers concussion when the meeting with an old friend and his drover accompanying. Apparently jealous, the insecurity of Soropita hides a vanity. This article seeks to demonstrate the way how the relationship between Soropita and Doralda dialogues with the three meanings of love that the Greek lexicon supports: Eros, Philia and Agape, according to the contemporary philosophers André Comte-Sponville and Paul Ricoeur.
\end{abstract}

Keywords: Guimarães Rosa; love; Eros; Philia; Agape.

Sexta narrativa do conjunto Corpo de Baile (1956), de Guimarães Rosa, "DãoLalalão" provoca na imaginação do seu leitor o despertar dos sentidos corporais. Explorando o elemento erótico contido no tato, no olfato e na audição, a narrativa rosiana, num primeiro momento, acende a imagética da sensualidade. Potencializados na vida do casal Soropita (um ex-boiadeiro e matador de jagunços), e Doralda (uma ex-prostituta), o aguçar desses sentidos camuflam, no entanto, um receio no antigo pistoleiro: a possibilidade de a ex-meretriz ser reconhecida pela antiga profissão. Incapaz de contornar a própria insegurança, Soropita enfrenta o medo da desonra ora com ponderação, ora com brutalidade. Assim resume o enredo de "Dão-Lalalão", Maria da Glória Bordini (ZILBERMAN, 2007, p. 101).

\footnotetext{
${ }^{1}$ Doutoranda em Teoria e História Literária pelo IEL/Unicamp.
} 
Na primeira sequência, o sertanejo Soropita retorna para o lugarejo chamado Ão, vindo de outro, Andrequicé [...]. Na segunda sequência, paralela à primeira, Soropita reencontra um amigo de anos, Dalberto, e outros tropeiros [...]. Na terceira sequência, Soropita convida os vizinhos e o amigo para jantar, observando cada gesto de Dalberto e Doralda [...]. Na quarta sequênica, cujo paralelismo com a anterior se dá no plano do ciúme e da prova, na manhã seguinte, Dalberto se vai, mas Soropita está desinquieto.

Composto por quatro sequências narrativas, o conto entrelaça presente e passado, ato e memória, fato e devaneio entre a materialidade dos acontecimentos e ressonância deles interior do personagem principal, que se pergunta incessantemente pela possibilidade de o passado da esposa ser revelado quando do encontro com um velho amigo. Bento Prado Jr. assim descreve o enredo do conto.

Mas examinemos mais de perto o personagem central de "DãoLalalão": a estória nos fala de Soropita, boiadeiro, que volta de Andrequicé, sozinho, para sua casa, no Aõ. Ao longo de sua viagem, rumina sua existência, sobretudo a oposição entre o áspero universo do trabalho e da luta e o universo doméstico do prazer - a figura de Doralda, sua mulher. A meio caminho, encontra-se com Dalberto, antigo amigo, e o conduz para casa. Formula-se então a questão [...]: teria Dalberto, ou algum de seus companheiros, conhecido Doralda, quando ainda tinha o nome de Sucena e era moça de vida airosa? A trama se desencadeia no ritmo rápido do ciúme até o seu desfecho violento. (PRADO JR., 1985, p. 202)

Numa breve revisão bibliográfica sobre "Dão-Lalalão", o consenso sobre o apelo erótico de Doralda e os decorrentes ciúmes de Soropita nunca são desmentidos. Devido aos detalhes confessionais com que o narrador descreve a relação sexual do casal, resgatando inclusive os antigos clientes da meretriz, os ciúmes do marido transbordam em imagens voluptuosas que beiram à promiscuidade. A própria esposa testemunha a obsessão do marido: “'-Tu conheceu os homens, mesmo muitos?' '- Aos muitos, Bem. Tu agora está com ciúme?"” (ROSA, 2016, p. 84).

Do reencontro com Dalberto à despedida do amigo, Soropita não se cansa de efabular a eventual descoberta do meretrício, reacendendo em si uma antiga fragilidade: não o mero ciúme da antiga profissão de Doralda, se não a honra da sua esposa, como deixa transparecer: "Tu, preto, atrás de pobre de mulher, cheiro de macaco..." (ROSA, 2016, p. 93). Sobre a reverberação desse encontro inesperado no psíquico de Soropita, comenta Bento Prado Jr. (1985, p. 202): "[...] o personagem é visado e descrito como uma consciência que se demora na recapitulação de sua existência: viagem interna no tempo, que se desenvolve paralelamente a vigem exterior, que percorre o espaço da estrada real, palmilhada pelo cavalo".

Caso emblemático da quimérica emulação de Soropita é com o senhor de terras, Sabarás, com quem Doralda esteve logo após ter conhecido Soropita. O duelo final com o preto Iládio apenas mimetiza tamanha suspeita. Sob o cunho racial, Soropita vincula o antigo cliente de Doralda com Iládio, o tropeiro amigo de Dalberto. Sobre a gratuidade dessa associação, argumenta Renata Eichenberg:

nesse momento também [Soropita] esclarece muitas dúvidas quanto aos homens que andaram com Doralda, principalmente os negros. Iládio 
não estivera com ela, mas o negro Sabarás, sim, como já sabia. Por isso, Soropita associa um ao outro, imaginando Iládio na cama com Doralda. O preconceito racial é tão forte na personagem quanto sua própria insegurança. (ZILBERMAN, 2007, p. 119)

Embora seja possível enveredar pela temática racial - atual e pertinente enxergamos na fortuita associação menos um índice discriminatório de Soropita, que o desespero de manutenção de uma integridade - desespero esse sintoma de sua própria vulnerabilidade. Em termos gerias, a pesquisadora Suzi Sperber define a mola propulsora do ciclo no qual se insere "Dão-Lalalão":

Guimarães Rosa entende que a escrita registra as progressivas mudanças com relação à compreensão possível do mundo - e do amor e da ação humana. Daí que Corpo de Baile represente uma complexa unidade cicular, cíclica, em movimento espiralado, começando e terminando com a personagem Miguilim (em "Campo Geral" e "Buriti"), e todas as narrativas girando em torno de nuanças do amor. O ciclo representa a unidade na diferença. (SPERBER, 2015, p. 95)

Nesse sentido, qualquer esforço em justapor a escrita rosiana às exigências dos lugares de fala contemporâneos acaba por desmerecer a dimensão do conflito de Soropita. Preservar a dignidade da esposa numa narrativa ambientada na transição do arcaísmo do sertão ao ineditismo da cidade grande por si só radiografa uma sociedade multifacetada. Mais do que fazer valer as leis patriarcais, ou seu oposto, denunciar a escravatura, Guimarães Rosa parece ocupar-se do resgate de vidas consideradas perdidas - sejam caipiras ou citadinas. Daí o tom pejorativo do epíteto preto Iládio ser antes de tudo o sintoma de uma insegurança. Em outras palavras, nada mais ameaçador à virilidade de um homem que outro homem. Vejamos.

Ao longo da viagem de volta ao Ão, três são as menções à debilidade experimentada por Soropita. A cada fraqueza, uma reação. Na primeira vez em que hesita 2 , "Soropita sem momento se escapava da cama, pressurado, foi-se vestindo" (ROSA, 2016, p. 39). Da segunda vez", já com Doralda, Soropita "[...] ocultando caçou jeito de aprender a respeito daquelas matérias que se tomavam: bico de picapau, verga de coatí, catuaba - tudo o que era duro, rijo, levantado e renitente, isso carregava virtude" (Idem). Da terceira e última menção ${ }^{4}$ à impotência sexual de boiadeiro e matador de jagunços, "Ao que ele teve, para se salvar, no instante, a ideia de invenção de imaginar e lembrar as coisas impossíveis, mundo delas; e Doralda, a língua, arrepios no pescoço dele, nas orelhas, como ele sabia - muito ditosamente que tudo se passou" (ibdem).

Somadas as cenas de impotência sexual ao senso de perigo constante em Soropira, "que sombreava um medo de susto, o receio de devir alguma coisa má, desastre ou notícia, que, na última da hora, atravessasse entre a gente e a alegria, vindo do fundo do mundo contra as pessoas" (ROSA, 2016, p. 37), temos no ex-boiadeiro e matador de jagunços um comportamento claramente reativo. Assim é que a frequência com que Soropita se vê vulnerável potencializa, paradoxalmente, sua rivalidade com quem não sofreria tamanho desgosto, justificando o expediente preto Sabarás e preto Iládio. Por extensão, se o

\footnotetext{
${ }^{2} C f$. Rosa (2016, p. 39): "um dia, sem saber os ajas, não pode, não podia, afracara, se desmerecendo. Mulher perguntou se ele queria beber gol, se doente estava. Não que não".

${ }^{3}$ Cf. Rosa (2016, p. 40): "mal a mal, com Doralda, uma vez, também tinha acontecido - felizmente foi só algum descaído de saúde, passageiro -: e foi um trago de sofrimentos".

${ }^{4} C f$. Rosa (2016, p. 40): "só muitos meses, adiante, a quebra de moleza quis voltar, mas que não foi grave".
} 
distintivo preto aos amantes de Doralda, antes de apontar uma falha no caráter, dissimula a própria falha de Soropita; o ciúme da esposa, igualmente, antes de alegar posse, sinaliza o zelo pela amada.

O cuidado excessivo com a integridade da esposa transborda não só nos ciúmes dos antigos clientes de Doralda, mas numa rivalidade da qual nem mesmo o velho amigo Dalberto escapa. Não são apenas os pretos o alvo da diligência de Soropita; Dalberto igualmente compõe o rol de inimigos virtuais.

Não podia, assim num momento, desvirar tudo, desmanchar aquela admiração de estima do Dalberto - então tudo o que ele Soropita tinha feito e tinha sido não representava coisa nenhuma de nada, não tinha firmeza, de repente um podia perder o figurado de si, com o mesmo ligeiro com que se desencoura uma vaca morta no chão do pasto... Mas, então... Então matava. Tinha de matar o Dalberto. Matava, pois matava. Soropita bebeu um gole de tranquilidade. (ROSA, 2016, p. 62)

Sobre a possibilidade de Soropita matar o próprio amigo, comenta Bordini (ZILBERMAN, 2007, p. 102): "para que o amigo não denuncie o passado de Doralda e não destrua a respeitabilidade que alcançou junto aos conhecidos, resolve matá-lo e passa o resto da viagem dividido entre a amizade de longa data e um ciúme feroz".

Apesar das constantes dúvidas assolarem a integridade de Soropita, o comportamento ingênuo de Dalberto lhe restitui a segurança. Quando ordena que o amigo acenda o cigarro de Doralda (ROSA, 2016, p. 74): “- Você mesmo acende, para ela, Dalberto, pode acender...", Soropita se dá conta da pureza, isto é, da absoluta falta de malícia do amigo ante a oportunidade. O teste de fidelidade atesta a amizade de Dalberto, restaurando a honra de Soropita, como postula Aristóteles, em Ética a Nicômaco (1155a): "a amizade também ajuda os jovens a afastar-se do erro [...]".

Tradução do termo grego philía, a amizade enquanto uma virtude é "um comportamento dirigido para o outro. É um momento essencial da vida feliz e implica reconhecimento, bondade e reciprocidade" (PICHLER, 2004, p. 201). Nela e por ela, Soropita apazigua seu conflito interno, assegurando-se: “[...] não podia nunca executar isso com o Dalberto, nem tinha os motivos da razão, estimava a muita amizade de um amigo amistoso" (ROSA, 2016, p. 75). Sobre o desdobramento dos significados do amor a partir do termo philía, reflete Aristóteles: “[...] os homens não podem conhecer-se mutuamente enquanto não houverem 'provado sal juntos'; e tampouco podem aceitar um ao outro como amigos enquanto cada um não parecer estimável ao outro e este não depositar confiança nele". O encontro inusitado com Dalberto coroa o senso de amizade em Soropita, como nos informa o narrador de Dão-Lalalão: "Amigo é: poucos, e com fé e escolha, um parente que se encontrava" (ROSA, 2016, p. 44).

Em contrapartida, ao relativizarmos os ciúmes de Soropita, não recusamos, forçosamente a pulsão sexual evidenciada na narrativa; antes entendemos os encantos de Doralda como polo complementar à impulsividade bélica de Soropita. Heloisa Vilhena de Araújo já associara intimamente o conto com a deusa do amor, Vênus.

Agora, em Dão-Lalalão, Vênus está na ascendente - é a estrela da manhã - e Marte vem emprestar-lhe um sombreado de guerra, sem, entretanto, dominar o texto. No final do conto, ao declinar Vênus, Soropita luta contra o preto Iládio, monstro de sua imaginação, criação 
de sua personalidade marcial, desconfiada, raivosa, triste, hipocondríaca e medrosa - na verdade, o preto era o "bom Iládio". (ARAÚJO, 1992, p. 107)

Adélia Bezerra de Menezes também já reconhecera o poder de guerra de Soropita, sem, no entanto, relacioná-lo diretamente ao patrono da guerra da mitologia clássica, como podemos ver na passagem: "[...] matador de muitas mortes, Soropita carregava no próprio corpo as marcas do seu passado, suas cicatrizes. Ele e sua mulher teriam, ambos, um passado a ocultar". Para a estudiosa, que investiga a ressonância da cultura hebraica em Dão-Lalalão, informada pelo próprio autor ${ }^{5}$, o conto teria como projeto uma releitura estranha e transgressiva do livro bíblico, Cântico dos Cânticos. Sem nos determos ao aproveitamento específico que Rosa faz dos versículos bíblicos, podemos concluir, por hora, que o impulso bélico de Soropita é antes a forma máxima da expressão da sua natureza, complementar ao erotismo profissional de Doralda.

Se é evidente o aproveitamento temático do livro bíblico em "Dão-Lalalão", é menos o enredo em si que se vê transportado do texto canônico ao texto ficcional que a atmosfera erótica determinante em ambos. Analisemos: fundidos, os protagonistas de Cântico dos Cânticos "[...] são dois jovens que se procuram, encontram-se e perdem-se para voltar a reencontrar-se num contínuo jogo de aproximações e partidas que se seguem e se entrelaçam", como descreve o pesquisador Gianmarco Catacchio (2012, p. 2). Já em "Dão-Lalalão", por mais que a viagem de volta ao Ão sugira o movimento de afastamento seguido de aproximação, seus protagonistas estão longe de se verem privados um do outro. Antes, a temática da união amorosa é que é facultada na transposição de personagens bíblicas a um matador e a uma prostituta. Sobre essa temática no Cântico dos Cânticos, comenta Catacchio:

pode-se dizer, pois, que os dois amantes, juntamente com todo o mundo que os rodeia e com o seu próprio amor, participam da essência de Deus, através de um movimento ascensional, capaz até de prescindir da intervenção divina directa, movido só pela força irrefreável da paixão que os empurra, corpo e alma, para uma dimensão superior. (CATACCHIO, 2012, p. 9)

Sobre a função de Eros para Platão, explana Sponville (SPONVILLE, 2009, p. 255): "de que se trata? De uma ascensão, de fato, mas espiritual, o que equivale a dizer, de um percurso iniciático e de uma salvação propriamente dita. É o percurso do amor, e a salvação pela beleza". Sobre esse amor, descreve o narrador de Dão-Lalalão (ROSA, 22016, p. 37): "chegava a casa, abria a cancela, chegava à casa, desapeava do cavalo, chegava em casa. A felicidade é o cheio de um copo de se beber meio por meio; Doralda o esperava".

Ora, não diríamos o mesmo da intensidade da relação do matador de jagunços com a prostituta? Não seria o amor o motor desse relacionamento que impulsionaria Soropita para fora da bandidagem e Doralda para fora do meretrício? Se sim, então, como numa espécie de contrabando da ambiência sensualizada de Cântico dos Cânticos, em "DãoLalalão" a união amorosa antes de ser problematizada, é tão somente tematizada. Em compensação, o relacionamento de Soropita com seus iguais, isto é, com os homens

${ }^{5}$ Cf. BIZZARRI, E.J. Guimarães Rosa: correspondência com seu tradutor italiano. São Paulo: T.A. Queiroz, 1980 [p. 50]: “diluídas, aliás, nas páginas 537/540, perpassa uma espécie de paráfrase do Cântico dos Cânticos". 
Dalberto, Sabarás e Iládio, é que é de fato problematizado ante a ameaça de uma eventual desonra. Obstinadamente questionado pelo seu o senso de perigo aguçado, o complexo relacionamento de Soropita com seus pares exige do protagonista um apaziguamento.

Assim é que da exaustão com que Soropita salvaguarda a antiga atividade da esposa, depreendemos que a narrativa rosiana do encontro de um casal um tanto atípico dialoga com o flagrante de Ares (o patrono da guerra) com Afrodite (a encarnação do desejo), descrito na Odisseia (Od., VIII, 266-364). Entendemos que, embora seja possível e mesmo evidente encontrarmos os vestígios da tradição judaico-cristã na obra de Guimarães Rosa, em Dão-Lalalão, em especial, o conto trata menos da transgressão sexual, como argumenta Meneses, do que dos desdobramentos de um relacionamento afetivo, sexualmente transgressor. A comparação entre a narrativa fundante da literatura, a Odisseia, e o conto rosiano, explica alguma coisa da relação apimentada de Soropita com Doralda.

No episódio homérico, ficamos sabendo que Afrodite trai o esposo - Hefesto, com o amante - Ares. Isto quer dizer que para o imaginário grego do ciclo homérico, o puro impulso sexual na figura de Afrodite não chega a formar um par, um casal, com o puro impulso bélico representado por Ares. Sobre a belicosidade de Ares, explana Burkert:

Ares is apparently an ancient abstract noun meaning throng of battle, war. The adjective derived from it,areios, occurs with remarkable frequency: there is a Zeus Areios, an Athena Areia, an Aphrodite Areia, and in Mycenaean there is apparently a Hermaas Areias as well, and then there is the Ares Hill, Areios pagos, in Athens. In Homer ares is used for battle; formulaic expressions are found such as 'to stand fast against sharpares', 'to stir up sharp ares', 'to measure one's strength in ares', and 'to kill through ares' at the same time, however, Ares is an armoured, brazen warrior whose war chariot is harnessed by Fear and Terror, Phobos and Deimos; he is overwhelming, insatiable in battle, destructive, and man-slaughtering. Since a hero is a warrior, he is called a branch of Ares; the Danaoi are followers of Ares and Menelaus in particular is dear to Ares and like Ares in battle. (BUERKERT, 1985, p. 148)

Antes, desejo erótico e sede de guerra, juntos, são motivo de zombaria dos demais deuses do panteão ${ }^{6}$, que assistem às gargalhadas o flagra que Hefesto foi capaz de fazer. Sobre o deus coxo, patrono do artifício, comenta a helenista americana, Eva Brann, em Homeric Moments:

he [Hephaestus] is the most physically vivid of the gods. He is severely crippled; his epithet is "Crook-foot." He is the only god whose deeds have had physical consequences: Zeus had hurled him from Olympus for helping his wife Hera in one of their continual quarrels. He fell all day to a hard landing, and Thetis took him into her home beneath the sea and nursed him for nine years, while he made fine jewelry for her. On Olympus he is a buffoon, huffing and puffing about as a wine server, arousing the gods' friendly-cruel "unquenchable laughter." He has been married to Aphrodite (of all divinities) - the goddess whose domain is sexual attraction, but who is for Homer a slightly ignoble female,

\footnotetext{
${ }^{6}$ Cf. HOMERO, Odisseia, VIII, 325-327. Trad. de Christian Werner. São Paulo: Cosacnaify, 2014: "pararam no pórtico os deuses, oferentes de bens; / e riso inextinguível irrompeu entre os deuses ditosos / ao verem as artes de Hefesto muito-juízo".
} 
laughable in battle and faithless in bed. She tries to deceive him with Ares, the brawny god of war, and on this occasion the artificer-god is the cause and not the butt of the gods' laughter, as he devises a net with which he entangles them in uninterruptible congress. (BRANN, 2002, p. 79)

Assim, a troça da traição de Afrodita, no plano divino, resulta em condenação, no plano humano, caso de Clitemnestra (Od., XI, 405-434). Em outras palavras, a união do puro impulso sexual (relativo à Afrodite) com o puro impulso bélico (associado a Ares) é freada, no mundo homérico, através da rede elaborada por Hefesto. Sobre a habilidade técnica do deus coxo, comenta Burkert: "Hephaistos the god has crippled feet, making him an outsider among the perfect Olympians; for this there are realistic and mythological explanations; special powers are marked by a special sign" (BURKERT, 1985 p. 147). Assim é que a claudicância de Hefesto o aproxima da condição humana (a imperfeição), mimetizando, em última instância, o limite da volúpia. Sobre a recepção do episódio épico na sociedade homérica, elucida a helenista Sarah Pomeroy:

Homer's attitude toward women as wives is obvious in his regard for Penelope and Clytemnestra. Penelope wins the highest admiration for her chastity, while Homer entrusts the ghost of Agamemnon to describe Clytemnestra`s infidelity in reproachful terms. (POMEROY, 1975, p. 21)

Desse modo, se por um lado é incontestável que "Soropita se entrega ao ruminar das sensações que lhe advêm do campo. [...] Os perfumes das flores, arbustos e ervas, o voo dos pássaros, os campos de milho, os canaviais, os riachos e tantas outras cenas cotidianas do sertão", como argumenta Elissandro Lopes Araújo; por outro, é igualmente irrefutável que a sinestesia sofrida pelo ex-boiadeiro lhe determina um modo de ser que garante estabilidade e respeitabilidade ao seu relacionamento com uma ex-prostituta. Dialogando com o episódio do flagra da traição de Afrodite, a capacidade de Soropita em sentir e avaliar ao mesmo tempo é análoga à rede de Hesfesto. Dito de outro modo, o que possibilita e condiciona esse casamento é justamente o comportamento ponderado de Soropita, pois, afinal, "havia mais de três anos Soropita deixara a lida de boiadeiro; e se casara com Doralda - no religioso e no cível, tinha as alianças, as certidões" (ROSA, 2016, p. 35). A respeito da capacidade de Soropita em conjugar experiência sensorial e reflexão, explicita Ana Maria Machado:

o caminho que chega ao Nome e dele se irradia, no caso de "DãoLalalão", não é racional, mas sensual e sensorial. Não é uma descoberta da ciência nem um esforço da consciência, mas tudo se passa na esfera da sensiênica, essa semiciência que funde sentir e pensar em novo verbo, sensear, que o autor cria e emprega mais de uma vez nesse conto [...] Nessa ciência dos sensos, nesse sentir de pensamentos ou nesse pensar de sensações é que tudo é novo, mesmo que aparentemente se repita, só repita, Soropita. (MACHADO, 2003, p. 188)

Termo forjado por Rosa, a sensiência característica de Soropita que lhe salvaguarda uma integridade constantemente sob advertência, estabelece um diálogo estreito com a noção específica de conhecimento oriunda do universo bíblico. Analisando o encontro do casal protagonista em o Cântico dos Cânticos sob a óptica simbólica da plenitude a partir da fusão dos princípios masculino e do feminino, a pesquisadora Maria José Caldeira do Amaral pontua: 
nos modelos bíblicos de pensamento, as palavras que traduzimos por "conhecer" e "conhecimento" exprimem um grupo mais complexo de atividades psíquicas. Conhecer é igual a experimentar. Saber do que se trata pela experiência. Os aspectos tanto sensitivos quanto intelectuais não possuem uma diferenciação em termos de sentido e não possuem a conotação ocidental dada pela filosofia de afirmação da verdade percebida. É a verdade experimentada, sentida, estendida ao outro e finalmente reconhecida. Conhecer com o coração é localizar nele a inteligência e a intuição. (AMARAL, 2005, p. 59)

Assim é que a senciência de Soropita intui e reconhece uma ameaça. Mesmo cismado com Dalberto, Soropita não se precipita, deixando livre a interação do amigo com a esposa, como diz: "- Doralda, Dalberto: agora estamos sozinhos, minha gente, vamos sem vexames de cerimônia... hora de festear!" (ROSA, 2016, p. 73). Porque cismado com Iládio, Soropita desafia o tropeiro, que se desculpa: "- Tou morto, tou morto, patrão Surrupita, mas peço não me mate, pelo ventre de Deus, anjo de Deus, não me mata... Não fiz nada! Não fiz nada!... Tomo benção... Tomo benção...” (ROSA, 2016, p. 93).

Desta forma, podemos compreender as atitudes de Soropita como respostas à ameaça a sua integridade, uma ameaça que sente internamente tanto na presença do hóspede amigo como na do tropeiro rival, apesar da diferença de tratamento entre um e outro. Sobre a resignação de Iládio, comenta Bordini:

como na viagem ele fantasiara cenas em que o grande negro teria conhecido carnalmente Doralda, o pistoleiro monta a cavalo, vai atrás do bando até Ão e desafia Iládio que, sem nada entender, mas temendo a fama do matador, se humilha, pedindo pela vida. Soropita, "numa paz poderosa", o respeito do povo à sua virilidade ainda garantido, volta para casa para recomeçar a vida outra vez, igual. (ZILBERMAN, 2007, p. 103)

Mas então, em que precisamente residiria essa diferença de tratamento entre amigo e amigo do amigo? A resposta talvez já tenha sido dada pelo próprio narrador que, valendo-se do uso dos parênteses, penetra na conversa paralela dos tropeiros e revela ao leitor a fama de que goza Soropita junto a eles (ROSA, 2016, p. 49): "- Amigo do Dalberto... Se viu, se vê. Não sei como se pode ser amigo ou parceiro de sonso-tigre. Como meu pai me dizia, de uns, menos assim: - Meu filho, não deixa a sombra dele se encostar na tua...".

Clímax da narrativa, a presunção de Soropita se precipita, como descreve o narrador (ROSA, 2016, p. 91): "o olhar atrevidado. E falou alguma coisa? - falou uma coisa - que não deu para se entender; e que seriam umas injúrias...”. Tendo como característica a sensiência, essa capacidade de suportar um sentimento e traduzi-lo em um entendimento, Soropita induz uma ofensa. Assim é que a sombra de Iládio esbarra na sombra de Soropita. Dessa topada nasce a suspeita de uma possível provocação. Reativo, o matador de jagunços resolve a aflição com uma ameaça de morte. À menor sombra de dúvida, o matador não titubeia: a impulsividade preserva instintivamente sua reputação. Da resposta de Iládio, a réplica de Soropita: "trepa em tua mula e desenvolve daqui..." (ROSA, 2016, p. 94).

Se, por um lado, não podemos aferir a ofensa de Iládio; por outro, a hipotética conversa paralela que o tropeiro travara com os camaradas, no dia anterior, informa aos 
leitores não apenas a fama de matador como os tribunais dos quais Soropita fora absolvido. Recordemo-nos do suposto murmúrio dos tropeiros, motivo suficiente para a sombra de Iládio encostar na de Soropita (ROSA, 2016, p. 49): "amigo do Dalberto... Se viu, se vê. Não sei como se pode ser amigo ou parceiro de sonso-tigre. Como meu pai me dizia, de uns, menos assim: - Meu filho, não deixa a sombra dele se encostar na tua!...".

Quando da procura por Dalberto, na manhã seguinte, o vocativo de Iládio “-Eh, Surrupita!...", seguido da explicativa "- e de um lanço estendia a mão, ria uma risadona, por deboche, desmedia e envergadura dos braços" (ROSA, 2016, p. 91), entrega o tropeiro à valentia do ex-jagunço. Ao olhar atrevidado de Iládio, Soropita se insurge: "homem ele era, tinha Doralda e os prazeres por defender, e seu brio mesmo, ia, ia em cima daquele negro, mesmo sabendo que podia ser p'ra morrer!" (ROSA, 2016, p. 92). À provocação, Soropita reage com vigor: perdoa Iládio. Recordemo-nos o decreto de Soropita ao tropeiro: "trepa em tua mula e desenvolve daqui..." (ROSA, 2016, p. 94).

Forjado pelo cristianismo, o termo ágape, que traduz a misericórdia contida no amor, é o que parece mover a sensiência de Soropita. Como explana Sponville (SPONVILLE, 2009, p. 133): "o amor? Quando ele existe, e quando subsiste depois da descoberta de uma falta, acarreta evidentemente a misericórdia, mas também a deixa sem objeto. Perdoar é cessar de odiar, é renunciar à vingança [...]". Ainda sobre a capacidade de amarmos não nossos objetos de desejo, nem nossos amigos; mas nossos próprios rivais, comenta Paul Ricoeur.

Não que a ágape ignore a relação com o outro, como demonstram os discursos sobre o próximo e sobre o inimigo; mas ela inscreve essa relação de busca aparente de equivalência subtraindo-a do julgamento. [...] Com o julgamento cai o cálculo, e com o cálculo a preocupação. A despreocupação da ágape é o que lhe permite suspender a disputa, até mesmo a justiça. $\mathrm{O}$ esquecimento das ofensas que ela inspira não consiste em afastá-las, ainda menos em reprimi-las, mas em "deixá-las ir", segundo a expressão de Hanna Arendt ao falar do perdão. (RICOUER, 2006, p. 235)

Nesse sentido, a sensiência de Soropita desperta nesse homem marcado pela impulsividade um senso de moderação. Uma vez demitida a vida de boiadeiro, essa sensiência imprime em Soropita uma disposição ligeiramente reflexiva. Sua capacidade de traduzir o fato experimentado em imagens e com elas tecer uma breve compreensão narratológica do acontecimento, origina em Soropita um entendimento. Tal entendimento redime tanto sua agressividade bélica quando uma alteridade aviltante. Furtando-se ao imediato, Soropita transcende a vingança e perdoa. Sobre a eficácia do perdão, comenta o filósofo Olivier Abel (1993).

Alors, comment non pas échapper, mais être à la hauter de l'irréversible? Ici encore c'est la sagessa du pardon qui devrait intervenir. On se souvient que le pardon fait coexister les points de vue antagonistes em construisant, sur le renoncement de chacun d'eux à la validité exclusive, une sorte de mixte, de compromis entre eux. Ce faisant déjà le pardon rapprochait des champs de signification éloignés, des sphères de justification hétérogènes, et désignait um monde possible où eles cohabitent. On perçoit ainsi vivement combien la sagesse est um travail de l'imagination. 
Com a sujeição de Iládio, Soropita triunfa, garantindo interiormente a paz no Ão, uma vez que "Adivinhara aquele lugar, ali, viera, comprara uma terra, uma fazenda e quase farto remedeio; dono de seus alqueires" (ROSA, 2016, p. 35). O motivo, então, do comportamento desconfiado de Soropita, que o leva a agir com moderação com o amigo Dalberto e com brutalidade com o rival, o preto Iládio, reside mais na reputação de Doralda e na sua própria, ou seja, na dignidade do seu relacionamento, que numa patologia ciumentada do personagem. Dito de outro modo, para que o encontro das potências do desejo e da guerra pudesse perdurar, constituindo-se em um casamento, é preciso aos amantes legitimar essa relação. Assim, os ciúmes do passado de Doralda são apenas o indício de uma questão ainda mais complexa no interior de Soropita: o reconhecimento e a legitimidade da união de um matador com uma prostituta, mesmo que desvencilhados das respectivas profissões.

Numa leitura mais atenta, as informações sobre o passado de Soropita levam a crer que a honra é para esse homem acostumado a matar equivalente a sua virilidade. $\mathrm{E}$ essa virilidade, por sua vez, decisiva para seu instinto vital. O trecho a seguir, embora longo, descreve os momentos em que Soropita sofre de impotência sexual, incidindo luz sobre o obscuro motivo da violência, paradoxalmente.

Mas ele não aceitava de ficar ali, fechando os olhos, num aporreado inteiro, pavoroso fosse mandraca, podia durar sempre assim, mas então ele suicidava; e sobre surdo passava o pensamento daqueles homens, no Brejo do Amparo, aqueles valentões, e os outros - ele não queria o reino dos amargos, o passado nenhum, o erro de um erro de um erro. Não queria, porque suportava. (ROSA, 1988, p. 28; grifo nosso)

Traduzida nos termos de uma falta cometida, o erro da impotência, ou antes, o erro da resignação ante a impossibilidade do gozo sexual, é intimamente associada ao comportamento desdenhoso daqueles valentões, na acepção mais pejorativa do léxico. Para Soropita, entretanto, a dificuldade do gozo é sofrimento, remediado pela incessante e profícua imaginação, como nos relata o narrador (ROSA, 2016, p. 40): "ao que ele teve, para se salvar, no instante, a ideia de invenção de imaginar e lembrar as coisas impossíveis, mundo delas; e Doralda, a língua, arrepios no pescoço dele, nas orelhas, como ela sabia - muito ditosamente que tudo se passou".

Assim, se a fabulação salvou Soropita de uma eventual impotência sexual, a própria relação sexual do par salvou Doralda da prostituição e Soropita da bandidagem. Embora a ex-prostituta não negue certo prazer na profissão, como o conto registra (ROSA, 2016, p. 84): “- Mas você, você gostava!" / “- Gostava, uai. Não gostasse, não estava lá...”. O ineditismo da afeição da profissional do amor pelo cliente é o impulso do relacionamento. E a amizade confirmada com Dalberto, que admira a vida de Soropita, e a condolência com Iládio, que reconhece sua superioridade bélica, legalizam esse casamento, mais do que a cerimônia religiosa e o registro civil.

Livro sapiencial, Cântico dos Cânticos enquanto matriz imagética de "DãoLalalão" funciona como fiador da temática amorosa sensualizada do conto rosiano. A certa altura, "Soropita em soberbas se alegrando: de ver a que ponto Doralda queria que o Dalberto notasse o qunato ela dele e ele dela se gostavam" (ROSA, 2016, p. 76). E não seriam esses os versos divinos, "Eu sou do meu amado/meu amado é meu" (Ct 2,16)? É o contrabando dos versos bíblicos que avalia o lastro do relacionamento entre um matador e uma prostituta, de um casamento sexualmente transgressor por natureza. Sobre a fusão do princípio masculino ao princípio feminino em o Cântico dos Cânticos, comenta Maria 
José do Amaral (2005, p. 64): “em seguida, a personagem feminina introduz a imagem deificada pela união - anima e animus: a amada é porta-voz da união e sabe que o amado é a sua própria alma, assim como ela é a própria alma do amado".

Tendo sido selada com caracteres sacros, resta ainda à união afetiva de Soropita e Doralda ser reconhecida no mundo dos homens. Assim é que Dão-Lalalão versa sobre a sedução de Doralda e os ciúmes de Soropita para tratar da escolha que um fez pelo outro. Em outras palavras, o suposto comportamento ciumento de Soropita não é senão seu esforço em assegurar respeitabilidade à vida do casal, impensável tanto para uma meretriz quanto para um pistoleiro. Eis, então, a transgressão em Dão-Lalalão: o casamento de uma prostituta com um assassino. Antes de acusarmos Soropita de racista, consideremos o esforço de manutenção da integridade desse relacionamento e a intenção do casal em permanecer no povoado do Ão. Incertos de onde estão, e considerando a fuga para um lugar ainda mais retirado, o Campo Frio, reflete Soropita: "Um homem não é um homem, se escapa de não pensar primeiro na mulher" (ROSA, 2016, p. 89).

\section{REFERÊCIAS}

ABEL, O. Ricoeur et la question tragique. Études Théologiques et Religieuses, Montpelier, $\mathrm{n}^{\mathrm{o}}$ 68, 1993. http://olivierabel.fr/ethique-et-politique/ricoeur-et-la-question-tragique.php.

AMARAL, M.J.C. Imagens de plenitude na simbologia do Cântico dos Cânticos. Último Andar, São Paulo, 13, 2005.

ARAÚJO, E.L. O baile de Eros em Dão-Lalalão: o projeto estético da novela roseana. http://www.cultura.ufpa.br/rcientifica/artigos cientificos/ed 08/pdf/elissandro araujo.pdf.

ARAÚJO, H.V. de. Raiz da alma. São Paulo: Edusp, 1992.

ARISTÓTELES. Ética a Nicômaco. Trad. Bras. São Paulo: Abril Cultural, 1973.

BÍBLIA SAGRADA Trad. Bras. São Paulo: Paulus, 1990.

BIZZARRI, E. J. Guimarães Rosa: correspondência com seu tradutor italiano. São Paulo: Instituto Cultural Ítalo-Brasileiro, 1980.

BORDINI, M. da G. "Dão-Lalalão" - assim é se lhe parece. Em: ZILBERMAN, R. (Org.). Corpo de Baile: romance, viagem e erotismo no sertão. Porto Alegre: EDIPUCRS, 2007.

BURKERT, W. Greek Religion. Harvard: Blackwell Publishing, 1985.

CATACCHIO, G. O cântico dos cânticos, ou a sacralidade do amor humano no mais terreno dos livros sagrados. Estrema [Revista interdisciplinas de humanidades], www.estrema-cec.com.

COMTE-SPONVILLE, A. Pequeno tratado das grandes virtudes. Trad. Bras. $2^{\mathrm{a}}$. ed. São Paulo: Martins Fontes, 2009.

EICHENBERG, R.C. "Dão-Lalalão": entre andanças poéticas. Em: ZILBERMAN, R. (Org.). Corpo de Baile: romance, viagem e erotismo no sertão. Porto Alegre: EDIPUCRS, 2007.

GONÇALVES, H.M. Um olhar indiscreto e desconstrutivo sobre as interpretações do Cântico dos Cânticos. Inclusividade, 2, ano 1, n. 2, 1-26, 2002. Disponível em http://www.dm.ieab.org.br/recursos/teologia/um_olhar_indiscreto_cantico_dos_canticos_humbe rto.pdf.

MACHADO, A.M. Recado do nome: leitura de Guimarães Rosa à luz do nome de seus personagens. $3^{\text {a }}$. ed. Rio de Janeiro: Nova Fronteira, 2003.

MENESES, A.B. de. "Dão-Lalalão" de Guimarães Rosa ou o "Cântico dos Cânticos" do sertão: um sino e seu badaladal. Estudos Avançados, USP, v. 22, 255-272., 2008.

PICHLER, N.A. As três formas de amizade na ética de Aristóteles. Ágora Filosófica, ano 4, n. 2, 193-207, 2004. http://www.unicap.br/Arte/ler.php?art cod=1488.

PLATÃO. Diálogos V: O banquete; Mênon; Timei; Crítias. Trad. Bras. São Paulo: Edipro, 2010. POMEROY. S.B. Goddesses, whores, wives and slaves: women in Classical Antiquity. New York: Schocken Books, 1976.

RICOEUR, P. Percurso do reconhecimento. Trad. Bras. São Paulo: Loyola, 2006.

ROSA, J.G. Noites do Sertão. Rio de Janeiro: Nova Fronteira, 2016. 
SPERBER, S. Vida Ensinada - em belas palavras. Guimarães Rosa, leitor de Platão. Em: ROHDEN, L. (Org.). Entre filosofia e literatura: recados do dito e do não dito. Belo Horizonte: Relicário, 2015.

SCHÄFER, C. (Org.). Léxico de Platão. Trad. Bras. São Paulo: Loyola, 2012.

Artigo recebido em: fevereiro de 2018.

Aprovado e revisado em: agosto de 2018.

Publicado em: dezembro de 2018.

\section{Para citar este texto:}

MARCHELLI, Clarissa Catarina Barletta. Os desdobramentos do amor em Éros, Filía E Ágape em "Dão-Lalalão", de Guimarães Rosa. Entremeios [Revista de Estudos do Discurso, ISSN 2179-3514, on-line, www.entremeios.inf.br], Seção Temática [Discurso, arte e literatura - Parte II], Programa de Pós-Graduação em Ciências da Linguagem (PPGCL), Universidade do Vale do Sapucaí (UNIVÁS), Pouso Alegre (MG), vol. 17, p. 277-288, jul. - dez. 2018.

DOI: http://dx.doi.org/10.20337/ISSN2179-3514revistaENTREMEIOSvol17pagina277a288 